\title{
Patient Perception of Physician Attire Before and After Disclosure of the Risks of Microbial Contamination
}

Enoch C. T. So, ${ }^{1}$ Faraday H. F. Fung, ${ }^{1}$ Joshua K. H. Yeung, ${ }^{1}$ Lilian H. Y. Chow, ${ }^{1}$ Julio S. H. Kwok, ${ }^{1}$ Ruby L. Y. Lam, ${ }^{1}$ Tommy C. Y. So, ${ }^{1}$ Faye S. M. Yu, ${ }^{1}$ Dana Vackova, $\underline{2}$ Gilberto K. K. Leung ${ }^{3}$

\begin{abstract}
Background: The white coat is traditionally considered to be the appropriate attire for physicians but it may also be contaminated with microbes and act as a potential source of infection. We aimed to study patients' acceptance of physicians' attire, their underlying reasons, and their reactions to an educational intervention with regards to the risks of contamination. Methods: We conducted a voluntary questionnaire survey at a university teaching hospital in Hong Kong from February to July 2012. 262 patient-responses from adult inpatients and outpatients across various specialties were analysed. Results: White coats were highly favoured (90.8\%) when compared with scrubs (22.1\%), smart casual (7.6\%) and formal (7.3\%) wears. 'Professional image' and 'ease of identification' were the main attributes of the white coat. Most patients (92.2\%) would prefer doctors washing their white coats every few days, whilst $80.9 \%$ believed that doctors were actually doing so. After patients were informed of the potential risk of microbial contamination, white coats remained as the most favoured attire $(66.4 \%)$, but with scrubs doubling in popularity $(45.8 \%)$. Smart casual $(9.2 \%)$ and formal attire $(4.6 \%)$ remain the least accepted. Conclusion: Despite cross-infections being a significant concern within the healthcare environments, patients' predominant acceptance and perceived attributes towards the white coat were maintained after an educational intervention on the risks of microbial contamination.
\end{abstract}

Keywords: Clothing, Cross Infection, Patient Preference, Patient Safety (Source: MeSH-NLM)

\section{Introduction}

The white coat is commonly regarded as the attire that confers a sense of professionalism and authority within the healthcare industry. The history of white coat attire dates back to the late 19th century, when scientists were in the habit of wearing beige-coloured laboratory coats. Wanting to associate themselves with the scientific community in order to gain trust from the public, doctors began to adopt the laboratory coat as a sign of trustworthiness and the ability to provide empirically supported treatments. The white colour was later chosen as a symbol of purity and dedication to 'do no harm'. The white coat eventually became an important symbol of the synergy between the arts and science of Medicine. ${ }^{1,2}$ This practice has since spread to many countries and cultures all over the world, with the white coat being strongly associated with the image of western medical practitioners. The significance of and respect towards this attire is reflected by the "white coat ceremony", a ritual which many western medical schools carry out in the beginning of the school years to emphasize professionalism. ${ }^{3}$

However, there has been intensifying debates as to whether doctors should continue wearing white coats in the hospital setting. The major argument against it being that this formal attire can be subject to microbial contamination, hence a potential source of hospital-acquired infections. ${ }^{4.5} \mathrm{~A}$ recent cross-sectional study of white coats worn by physicians at a large teaching hospital showed that $23 \%$ of the coats were contaminated with Staphylococcus aureus, where $18 \%$ of these were Methicillin-resistant Staphylococcus Aureus (MRSA). ${ }^{6}$ In view of the growing concern, white coats have been banned in parts of United Kingdom (U.K.) since 2007 and the "bare below the elbow" policy was adopted in order to reduce the risks of contamination (Available from: http://webarchive.nationalarchives.gov.uk/20130107105354/http://www.dh.gov.uk/prod_ consum_dh/groups/dh_digitalassets/documents/digitalasset/ dh_078435.pdf, updated 2007, cited 2013 Sep 6).7-8 The American Medical Association, however, stopped short of banning white coats, opting for the advocation of a dress code that "minimize transmission of nosocomial infections, particularly in critical and intensive care units" (Available from: http://www. ama-assn.org/resources/doc/hod/a-10-bot-reports.pdf, updated 2010, cited 2013 Sep 6). This was presumably partly due to inconclusive evidence that the "bare below the elbow" policy would indeed translate to lesser nosocomial infection rates. ${ }^{9}$

This article aims to add weight to the argument by looking from the patient's point of view. In particular, the study aimed at elucidating the following four pieces of information: 1.) Patients' acceptance of physicians' attires; 2.) Their perceived values of the white coat; 3 .) Their preferred and perceived frequencies of white-coat cleansing; and 4.) Changes in patients' acceptance after an educational intervention concerning the potential risk of microbial contamination of doctors' clothing. 
Further understanding from the patient's perspective would allow us to gage the potential impact on patients should an alternative dress code be adopted in the future.

\section{Methods}

\section{Study design}

A voluntary questionnaire survey was conducted on a convenience sample of 264 patients at Queen Mary Hospital, a teaching hospital in Hong Kong, between February and July 2012. Patients were recruited from both inpatient wards and outpatient clinics of various specialties in the hospital. All but 2 patients who participated met the inclusion criteria of being aged 18 years or above, fully alert, mentally competent, and could read or speak Chinese at the time of the study. The 2 patients who did not meet these criteria were excluded from subsequent analysis. Subjects were briefed and given an information sheet regarding the nature of the study and their rights to refuse to participate, prior to providing verbal consent if granted. Each was given an anonymous non-guided questionnaire survey. Explanations of the survey items were provided upon the subjects' requests. The study was approved by the hospital's Institutional Review Board.

\section{The questionnaire}

Subjects were presented with a questionnaire as well as a set of photographs depicting 4 examples of physician attire (Figure 1). These included casual wear (A), scrubs (B), white coats (C) and formal wear (D). Each example attire was worn by a female and a male model with only slight variations allowed for common gender differences. The models' postures, facial expressions, hairstyles and their backdrops were kept consistent. Subjects were then asked to refer to the photographs to choose their accepted attire, and to rate the four sets of photographs on three aspects: professional image, friendliness, and cleanliness. Subjects were then asked to select their most accepted attire.

Subjects were then asked whether they deemed white coat necessary in different healthcare settings (public hospital, teaching hospital, private hospital and clinic), and why they thought doctors should wear white coats. We also asked the subjects for their preferred and perceived frequencies of white coat cleansing by doctors.

We then provided each subject with a standardized statement on the potential risks of microbial contamination on white coats and long sleeved shirts. The statement, translated from Chinese to English, was as follows: "Studies have shown that doctors, after contact with patients, can be colonized with infective agents on their clothing. In particular, white coats and other long sleeved attire contain the highest colonization rate. A study from a US hospital has shown that $4 \%$ of doctors have white coats colonized by antibiotic-resistant MRSA" ${ }^{6}$

Subjects were then asked to indicate their acceptance of different attires as well as their ratings on professionalism, friendliness and cleanliness again.

The questionnaire was designed and administered by the authors.

\section{Data collection and analysis}

Results of the questionnaire were coded into a pre-designed spreadsheet template with validation criteria. The results were analysed using SPSS (IBM version 19). Demographic information, including age, sex, education level, occupation, individual

Figure 1. Female and Male Doctors Dressed in 4 Different Attires (A: Casual, B: Scrubs, C: White Coat and D: Formal)

A

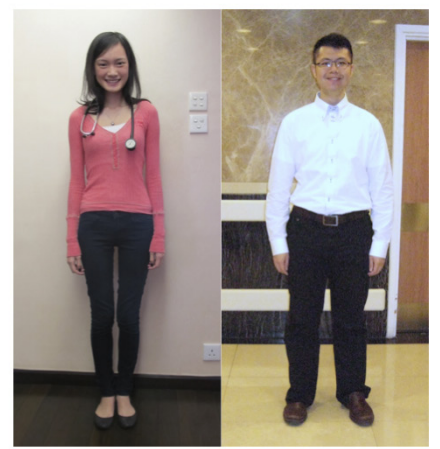

B

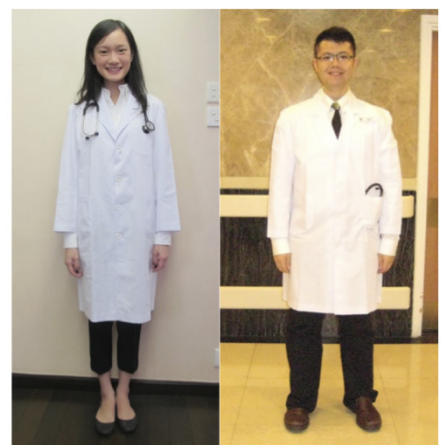

C

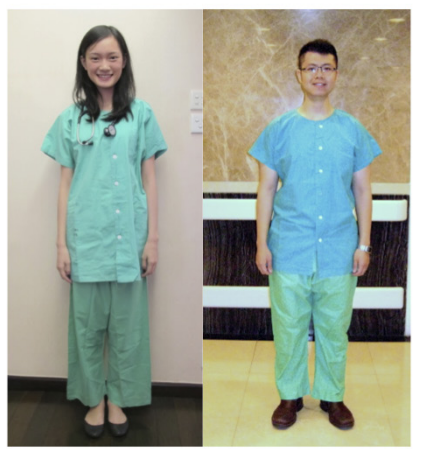

D

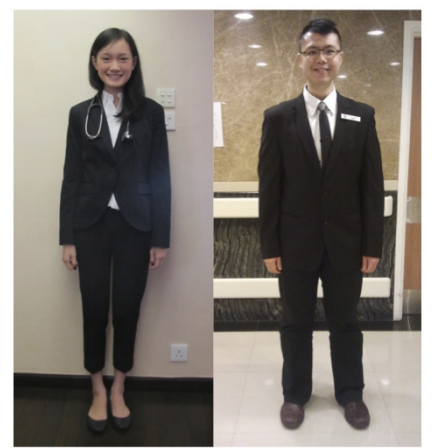


monthly income and hospital service location, were compared with the results of the surveys using chi-square tests. A statistical significance level of 0.05 was employed throughout the analysis. Patients' preferences pre- and post-disclosure of microbial contamination risks were measured on a Likert scale from 1 to 5 , and were compared using paired t-test.

\section{Results}

Patients' demographic characteristics are listed in Table 1. Overall, white coats were favoured by the majority of patients ( $n$ $=238$ or $90.8 \%)$, followed by scrubs $(n=58$ or $22.1 \%)$, smart casual $(n=20$ or $7.6 \%)$ and formal $(n=19$ or $7.3 \%)$ attire (Fi-

Table 1. Patient Socio-Demographic Characteristics and Hospital Service Lo cation when Surveyed

\begin{tabular}{lr}
\hline Characteristics & $\mathbf{n}(\%)$ \\
Cender & $111(42.4)$ \\
\hline Male & $151(57.6)$ \\
\hline Female & \\
Age Group & $93(36.5)$ \\
\hline$<40$ & $135(52.9)$ \\
\hline $40-64$ & $27(10.6)$ \\
\hline$>64$ & \\
\hline Education Level* & $148(56.7)$ \\
\hline Non-Tertiary & $113(43.3)$ \\
\hline Tertiary or Above & \\
\hline Personal Income per month (HKD \$) & $59(23.7)$ \\
\hline \$1,000 & $64(25.7)$ \\
\hline \$1,000 - \$9,999 & $64(25.7)$ \\
\hline \$10,000 - \$19,999 & $62(24.9)$ \\
\hline \$20,000 & $134(51.1)$ \\
\hline Hospital Service Location & $128(48.9)$ \\
\hline Inpatient & \\
\hline 0utpatient & \\
\hline
\end{tabular}

Note: Percentages from total patient population, $\mathrm{N}=262$.

* Tertiary education: Higher diploma, associate degree, bachelor's degree or postgraduate degree

Figure 2. Patients' Acceptance on Physician's Attire Pre- and Post Disclosure of Potential Microbial

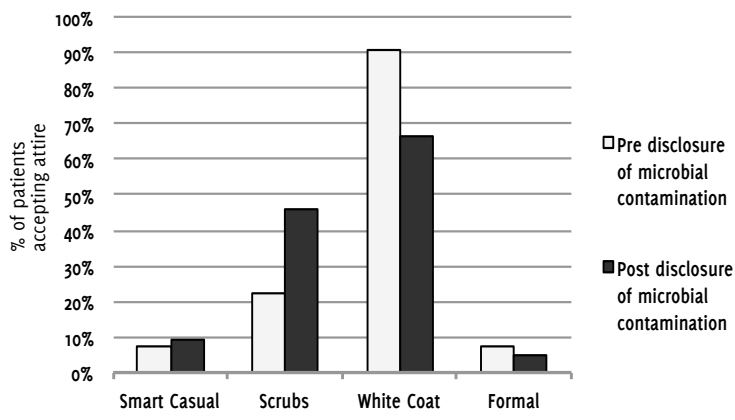

Note: Patients may choose to accept more than one attire. Percentages from total patient population, $\mathrm{N}=262$. gure 2). There were no significant differences between patients of different age groups, hospital service location and income levels.

The majority of patients opined that white coats should be worn by doctors in all healthcare setting, especially in public hospitals $(n=213$ or $81.6 \%)$ and teaching hospitals $(n=196$ or $75.1 \%$ ), followed by private hospitals ( $n=165$ or $63.5 \%$ ), and clinics $(n=139$ or $53.7 \%$ ). The differences between the four attires were statistically significant $(p<0.001)$ (Figure 3 ). 'Conferring a professional image' $(n=187$ or $71.4 \%)$ and 'Ease of Identification' ( $n=184$ or $70.2 \%$ ) were the two main reasons why patients would prefer doctors wearing white coats. Opi-

Figure 3. Patients' Agreement on whether White Coats should be Worn in Various Clinical Settings

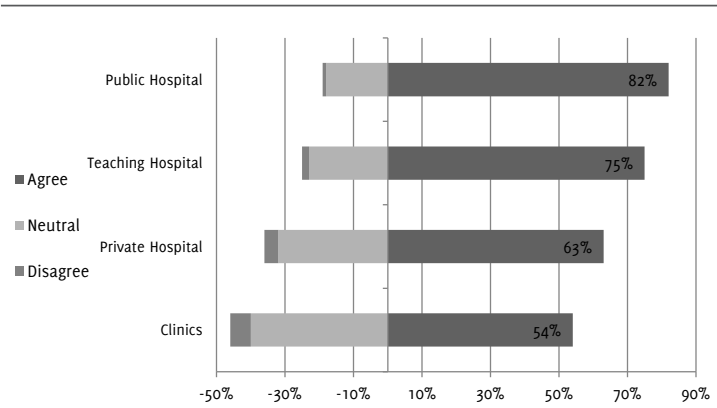

Note: Percentages from total patient population, $\mathrm{N}=262$.

nions were relatively more divided on 'Neatness' ( $n=141$ or $53.8 \%$ ) and 'Hygiene' ( $n=128$ or $48.9 \%$ ). 'Tradition' ( $n=93$ or $35.5 \%$ ) and 'Self-confidence' ( $n=40$ or 15.3 ) received relatively low ratings (Figure 4$)$. With regards to white coat cleansing, $92.2 \%(n=237)$ of patients would prefer doctors to wash their white coats every few days, and almost all $(97.7 \%$ or $n=251)$ preferred coats to be washed at least once a week. A similar

Figure 4. Patients' Perception of Positive Attributes Represented by the White Coat

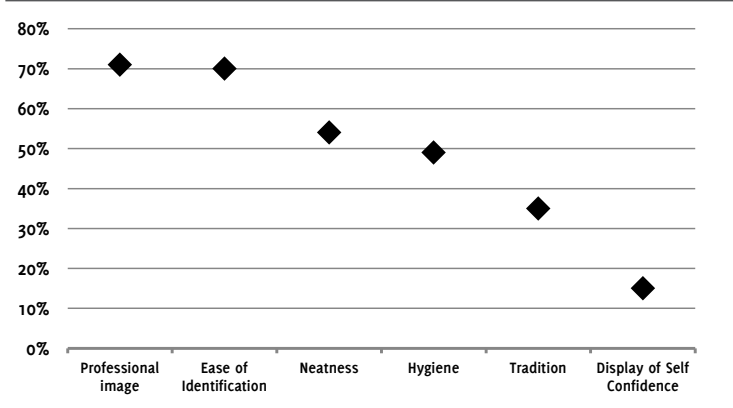

Note: Percentages from total patient population, $\mathrm{N}=262$.

majority ( $n=208$ or $80.9 \%$ ) believed that doctors would actually cleanse their white coats every few days (Figure 5).

After receiving the statement on the potential risks of contamination, the majority of subjects still ranked white coat as their most accepted dress code, but the proportion had decreased from $90.8 \%(n=238)$ to $66.4 \%(n=174)$. On the other hand, the acceptance for scrubs increased from $22.1 \%(n=58)$ to $45.8 \%(n=120)$. Acceptance for smart casual and formal attire remained less than $10 \%$ (Figure 2 ). Inpatients became more 
Figure 5. Patients' Estimated Frequency and Preference for White Coat Cleansing in the Healthcare Setting

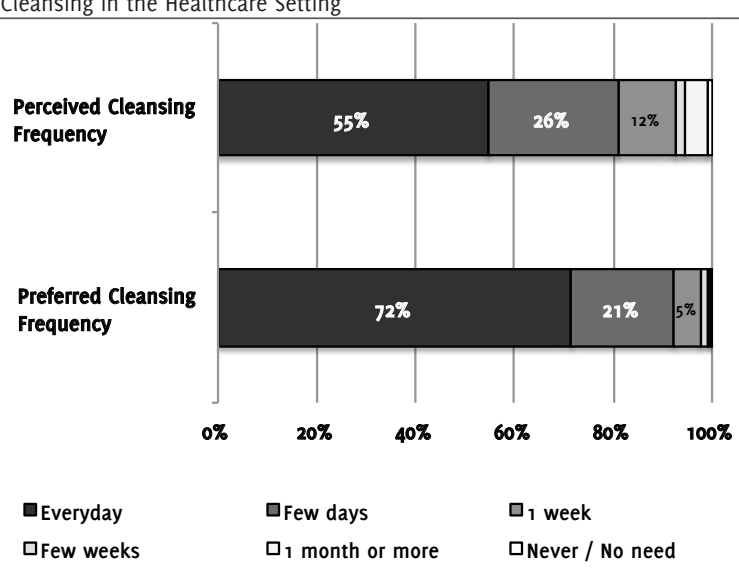

Note: Percentages from total patient population, $\mathrm{N}=262$.

likely than outpatients to accept scrubs post-disclosure $(55.2 \%$ vs $35.9 \%, p=0.002$ ). This difference was not observed pre-disclosure.

Following our intervention, the rating for cleanliness decreased for white coat (from 4.56 down to 4.27, p<0.001) and increased for scrubs (from 3.61 up to 3.84, p<0.001) (Table 2). Interestingly, a similar trend in the attire's 'professional image' rating was also observed for white coat (from 4.73 down to 4.62, $p=0.012$ ) and scrubs (from 3.63 up to $3.73, p=0.001$ ), despite the fact that the statement was not explicitly linked to this attribute. Scrubs were also deemed to be more friendly and acceptable post-disclosure (from 3.24 up to 3.39 , p<0.001).

Throughout the whole study, female patients consistently reported a higher preference and acceptance for white coats than their male counterparts, a finding that is not observed in other attires (Table 3). Prior to intervention, $95.4 \%$ of female patients showed acceptance to the white coat attire, as compared to $84.7 \%$ of the male patients $(p=0.003)$. The difference between genders were maintained post-intervention where statistically significantly more female patients would still accept physicians wearing white coats as compared to male patients $(72.2 \%$ vs $58.6 \%, p=0.021$ ). Moreover, female patients had greater acceptance for white coats in all four clinical settings, with the difference within public hospitals $(86.8 \%$ vs $74.5 \%, p=0.020)$ and teaching hospitals $(81.5 \%$ vs $66.4 \%, p=0.011)$ being statistically significant. No differences were found with regards to other demographic variables (data not shown).

\section{Discussion}

It is well known that patient perception of the healthcare professions, doctor-patient relationships and the concept of professionalism varies between societies and patient populations, and can be heavily influenced by social and cultural factors. Our locality is unique in the sense that it consists of predominantly a Chinese population whilst the healthcare system is modeled after the National Health Service (NHS) of the UK. To the best of our knowledge, this is the first study in Hong Kong to be conducted on this topic.

Table 2. Patient's Perception of Professionalism, Friendliness and Cleanliness by Type of Doctor's Attire Before and After the Disclosure of the Potential Risk for Microbial Contamination

\begin{tabular}{|c|c|c|c|c|}
\hline & $\begin{array}{l}\text { Smart Casual } \\
\text { Score }(95 \% \mathrm{Cl})\end{array}$ & $\begin{array}{c}\text { Scrubs } \\
\text { Score }(95 \% \mathrm{Cl})\end{array}$ & $\begin{array}{c}\text { White Coat } \\
\text { Score }(95 \% \mathrm{Cl})\end{array}$ & $\begin{array}{c}\text { Formal } \\
\text { Score }(95 \% \mathrm{Cl})\end{array}$ \\
\hline \multicolumn{5}{|c|}{ Professionalism $\$$} \\
\hline \multirow[t]{2}{*}{ Before } & 2.00 & 3.63 & 4.74 & 2.99 \\
\hline & $(1.88-2.12)$ & $(3.49-3.77)$ & $(4.66-4.81)$ & $(2.84-3.14)$ \\
\hline $\mathrm{p}$-value & 0.071 & $0.001^{*}$ & $0.012^{*}$ & 0.171 \\
\hline \multicolumn{5}{|c|}{ Friendliness $^{\S}$} \\
\hline \multirow[t]{2}{*}{ Before } & 2.94 & 3.25 & 4.03 & 2.61 \\
\hline & $(2.78-3.10)$ & $(3.12-3.38)$ & $(3.91-4.15)$ & $(2.47-2.76)$ \\
\hline$p$-value & $0.029^{*}$ & $<0.001^{*}$ & 0.681 & 0.613 \\
\hline \multicolumn{5}{|c|}{ Cleanliness $^{\S}$} \\
\hline \multirow[t]{2}{*}{ Before } & 2.68 & 3.61 & 4.57 & 3.12 \\
\hline & $(2.53-2.82)$ & $(3.47-3.75)$ & $(4.47-4.66)$ & $(2.96-3.27)$ \\
\hline \multirow[t]{2}{*}{ After } & 2.68 & 3.82 & 4.27 & 3.03 \\
\hline & $(2.50-2.83)$ & $(3.68-3.97)$ & $(4.12-4.41)$ & $(2.86-3.19)$ \\
\hline $\mathrm{p}$-value & 0.570 & $<0.001^{*}$ & $<0.001^{\star}$ & $0.015^{*}$ \\
\hline
\end{tabular}

Note: Score ratings measured by a 5-point Likert scale where 1 was the worst and 5 the best.

* $p<0.05$, Chi2 test.

$\S$ Patient's perception of each characteristic before and after disclosure of potential risk of microbial contamination

Abbreviations: $95 \% \mathrm{Cl}$ : $95 \%$ confidence intervals 
Table 3. Patients' Acceptance on Physician's Attire Pre- and Post-Disclosure and among Various Clinical Settings (for White Coat) by gender

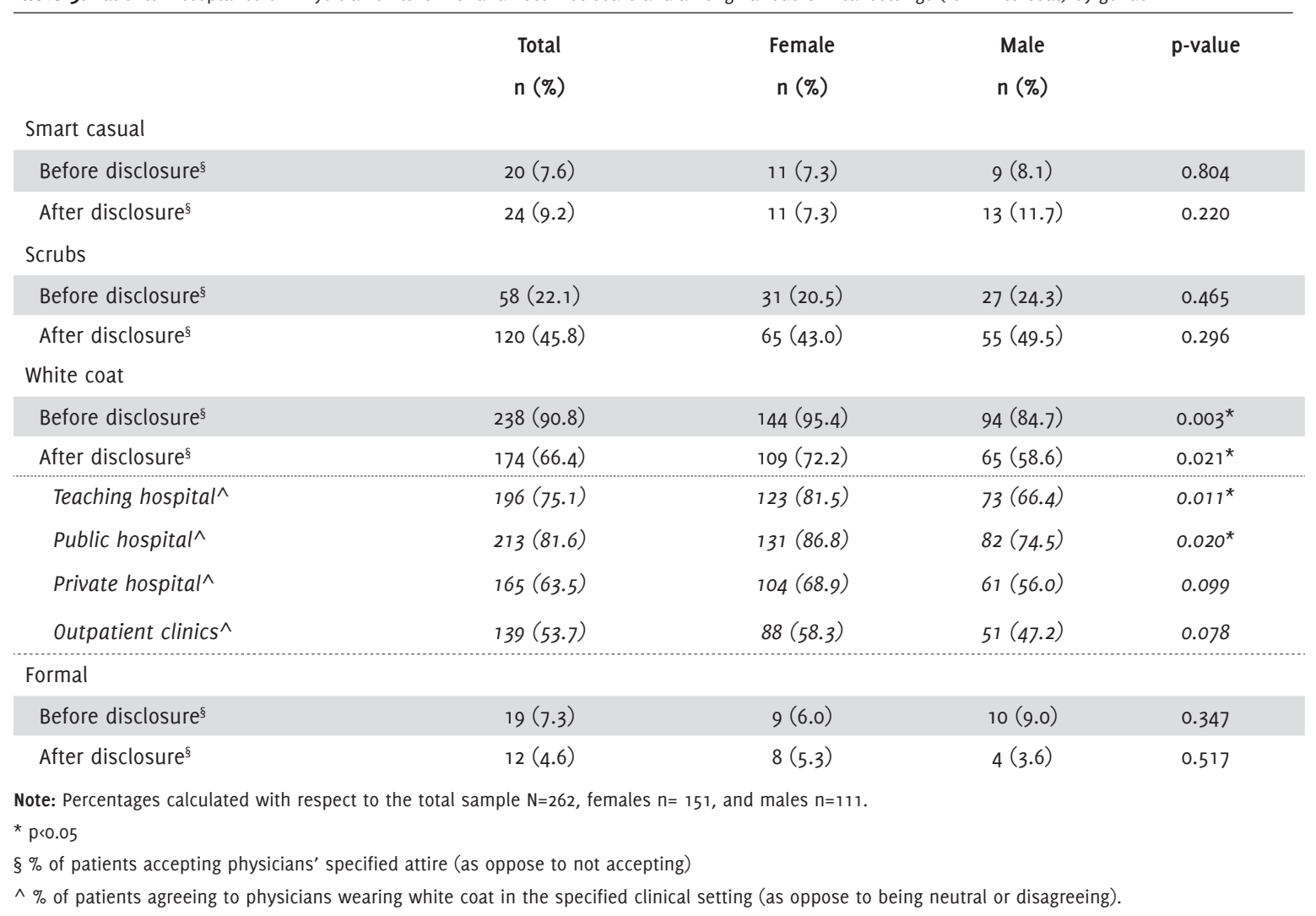

By and large our findings are consistent with those of international studies which showed white coats to be the most preferred, and casual wear the least favoured attires..$^{10-16}$ Lill's study in New Zealand where semiformal attire is the most preferred is a notable exception. ${ }^{17}$ There are, however, subtle differences in patients' perceptions between countries. For instance, 'hygie$n^{\prime}$ ' was found to be the dominant factor in determining attire preference in Japan, as opposed to 'professional image' in our study. ${ }^{12}$ Scrubs were also perceived to be more hygienic than white coats in Japan, in contrast to our local findings. When informed of the hygienic risks that "long sleeved white coats might be a vehicle for transmission of pathogens", Japanese patients readily reversed their preferences, and were overwhelmingly in favour of scrubs over white coat ( $58.4 \%$ vs $25.6 \%$ ). Similar observations of preference reversal were also observed in Shelton's study in the United Kingdom and Huetson's study in the United States. ${ }^{18,19}$ The same educational intervention, on the other hand, did not result in the same degree of preference reversal amongst patients in Hong Kong. White coats remained to be the more preferred attire despite post-disclosure. Female patients are also found to have a higher acceptance for white coats than the male counterparts in our study.

We surmised that the persistent preference for white coats amongst the local population may be partly due to the deep-rooted perception of 'professional image' associated with this attire, as indicated by the high score awarded to this item post-disclosure. Another plausible explanation may be that most patients believed doctors were cleaning their white coats at a preferred frequency. Therefore, although patients were aware of the risks of contamination, this could have been com- pensated for by a perceived practice of frequent cleansing. In this regard, it would be interesting to study whether the white coat cleansing practices amongst local doctors are indeed aligned with the perception. The strong preference for white coats post-disclosure may also be due to the relatively technical and non-specific nature of the statement on contamination risks, thus preventing patients from fully understanding the potential harm in using the coat. The observed phenomenon where female patients prefer white coat attire more than male patients remains to be an interesting area for future studies.

Nevertheless, it can be inferred from our findings that the white coat has its role in establishing a unique form of doctor-patient relationship. This has to be carefully considered and balanced against the potential risks of contamination and cross-infections. There are fine distinctions between the latter two. While white coat contamination has been clearly demonstrated, there has yet to be conclusive evidence linking contamination of white coat to an increased risk of hospital-acquired infections. ${ }^{4-6,20-21}$ On the assumption that there is such a causal link and/or that there is an attempt to adopt the U.K. "bare below the elbow" policy here, our findings indicate that there needs to be further enhancement of patient education on the potential risks of nosocomial infection to emphasize the priority of hygiene over other attributes, so as to facilitate patient involvement in improving their own safety.

The study has several limitations. Firstly, the sample size was relatively small and was confined to one institution. A larger sample size would reduce the potential bias due to locality and the institution's nature as a tertiary teaching hospital, making 
the results more generalizable to the community. Secondly, while we strived to deliver the education statement in a factual and impartial manner, it may be perceived as too technical for less medically educated patients to comprehend. It would be interesting to test variations of the educational statement with regards to contamination risks, and to study the impacts of different contents. Thirdly, the use of a single statement as an intervention has the downside of being too impersonal and distant as compared to other methods of delivery, for example pictures of cultured bacteria from contaminated attire. Patients may tend to overestimate their perceived tolerance to contaminated attires. Fourthly, disclosure of a single, negative fact may introduce a predictable shift in the participant's response, which makes it difficult to interpret the true risk from this study. Lastly, the questionnaire was developed by the investigators and has not been validated.

\section{Conclusion}

The white coat was found to convey a sense of 'professionalism', allow 'ease of identification', and was the patients' attire of choice for physicians. This predominant preference and the perceived attributes were maintained despite an educational intervention concerning the risks of microbial contamination. The majority of patients believed that doctors would clean their coats at a frequency preferred by the former. Cross-infections within healthcare environments are serious concerns. Further studies may focus on the potential risks to patients due to cross contamination, the practices of coat cleansing amongst professional personnel, and effective means of patient education to improve their awareness and safety.

\section{References}

1. Jones VA. The white coat: why not follow suit? JAMA. 1999;281(5):478.

2. Blumhagen DW. The doctor's white coat: the image of the physician in modern America. Ann Intern Med. 1979;91(1):111-116.

3. Huber SJ. The white coat ceremony: a contemporary medical ritual. J Med Ethics. 2003;29(6):364-6.

4. Loh W, Ng VV, Holton J. Bacterial flora on the white coats of medical students. J Hosp Infect. 2000;45(1):65-8.

5. Wong D, Nye K, Hollis P. Microbial flora on doctors' white coats. BMJ. 1991;303(6817):1602-04.

6. Treakle AM, Thom KA, Furuno JP, Strauss SM, Harris AD, Perencevich EN. Bacterial contamination of health care workers' white coats. Am J. Infect Control. 2009;37(2):101-5.

7. Kerr C. Ditch that white coat. CMAJ. 2008;178(11):1127

8. Bond L, Clamp PJ, Gray, K, Van Dam V. Patients' perceptions of doctors' clothing: should we really be 'bare below the elbow'? J Laryngol Otol. 2010;124(9):963-6

9. Henderson J. The endangered white coat. Clin Infect Dis. 2010; 50(7):1073-4. 10. Cherardi G, Cameron J, West A, Crossley M. Are we dressed to impress? A descriptive survey assessing patients' preference of doctors' attire in the hospital setting. Clin Med. 2009;9(6):519-24.

11. Rehman SU, Nietert PJ, Cope DW, Kilpatrick A0. What to wear today? Effect of doctor's attire on the trust and confidence of patients; Am J Med. 2005;118(13):1279-86.

12. Yamada Y, Takahashi 0, Ohde S, Deshpande GA, Fukui T. Patients' Preferences for Doctors' Attire in Japan. Inter Med. 2010;49(16):1521-26.

13. Cha A, Hecht BR, Nelson K, Hopkins MP. Resident physician attire: Does it make a difference to our patients? Am J Obstet Gynecol. 2004;190(5):1484-8 14. Gjerdingen DK, Simpson DE, Titus SL. Patients' and physicians' attitudes regarding the physician's professional appearance. Arch Intern Med. 1987; 147(7):1209-12

15. Chang DS, Lee $H$, Lee $H$, Park HJ, Chae $Y$. What to wear when practicing oriental medicine: patients' preferences for doctors' attire. J Altern Complem Med. $2011 ; 17(8): 763-67$

16. Dunn JJ, Lee TH, Percelay JM, Fitz JG, Goldman L. Patient and house officer attitudes on physician attire and etiquette. JAMA. 1987;257(1):65-8.

17. Lill MM, Wilkinson TJ. Judging a book by its cover: descriptive survey of patients' preferences for doctors' appearance and mode of address. BM]. 2005;331(7531):1524-7.

18. Shelton CL, Raistrick C, Warburton K, Siddiqui KH. Can changes in clinical attire reduce likelihood of cross-infection without jeopardising the doctor-patient relationship? J Hosp Infect. 2010;74(1):22-9.

19. Hueston W], Carek, SM. Patients' preference for physician attire: a survey of patients in family medicine training practices. Fam Med. 2011;43(11):643-7. 20. Wilson JA, Loveday HP, Hoffman PN, Pratt RJ. Uniform: an evidence review of the microbiological significance of uniforms and uniform policy in the prevention and control of healthcare-associated infections. Report to the Department of Health (England). J Hosp Infect. 2007;66(4):301-7.

21. Loveday HP, Wilson JA, Hoffman PN, Pratt RJ. Public perception and the social and microbiological significance of uniforms in the prevention and control of healthcare-associated infections: an evidence review. Brit J Infect Cont. 2007;8(4):10-21

\footnotetext{
Acknowledgments

We would like to thank Mr. Eric Chan from the School of Public Health, Li Ka Shing Faculty of Medicine, the University of Hong Kong for his statistical expertise. We would also like to thank Ms. Ching Tang and Mr. Simon Yan as models for our photographs.
}

Conflict of Interest Statement a Funding

The Authors have no funding, financial relationships or conflicts of interest to disclose.

Cite as:

So ECT, Fung FHF, Yeung JKH, Chow LHY, Kwok JSH, Lam RLY, et al. Patient Perception of Physician Attire Before and After Disclosure of the Risks of Microbial Contamination. Int J Med Students. 2013;1(3):109-14. 